DOI: $10.1515 / \mathrm{aa}-2017-0005$

\title{
Aesthetic distance as a form of liminality in selected short stories of
}

\section{American literature}

\author{
Natália Čechová
}

Natália Čechová is a $\mathrm{PhD}$ student at the Department of English and American Studies, Constantine the Philosopher University in Nitra. She is currently working on her thesis, entitled Aesthetic Distance in Contemporary Fiction. She is interested in literature of whatever country of origin and often spends time reading books containing inspiring and thought-provoking themes.

\begin{abstract}
Aesthetic distance is a phenomenon that has attracted a considerable amount of attention, especially since the first works of postmodernism came to light. Aesthetic distance is based on creating such works which - using certain artistic tools and techniques - break the illusion and thus inhibit readers from immersing themselves in the literary world portrayed in the work they read. As a result, aesthetic distance creates a liminal space, or an invisible but consciously perceivable border between reality, i.e. the world we live in and fiction, i.e. the world we want to relocate to and enjoy during the reading process.

The paper is based on an article by Bjorn Thomassen, in which he presents several types of liminality and states that the typology is not final. My aim is to prove that liminality can occur in literature as well, particularly in works built on aesthetic distance. In this matter, I focus on the reception theory of Wolfgang Iser, who studies literary texts from three perspectives: the text, the reader and the communication between the two. The theory is applied to selected short stories of American literature, which contain illusion-breaking features and thus may be viewed as liminal spaces.
\end{abstract}

\section{The concept of liminality}

Even though the concept of liminality was first introduced by Arnold van Gennep in his work Rites de Passage (1909) as an anthropological term used to describe and analyse the middle stage in various ritual passages (Thomassen, 2009, p. 5), the term has since been adopted in several other fields of study and disciplines, such as psychology, sociology, culturology, the study of ethnic, cultural and sexual minorities, as well as literature. Irma Ratiani explains that the concept of liminality comes from the Latin limen, which stands for "a threshold or boundary, a corridor between two different places" (Ratiani, p. 1). From this point of view, the liminal or boundary period may occur in various moments and situations, as suggested by 
Victor Turner, who is believed to have liberated the concept of liminality from its predominantly anthropological use and suggested its different types and uses (Thomassen, 2009 , p. 14) based on subject (i.e. who goes through the liminal period); time (i.e. how long the liminal period lasts); and space (i.e. where the liminal period occurs), as outlined by Thomassen in his study of the uses and meanings of liminality (ibid., p. 16).

At the centre of my attention now is the use of liminality in literature, which is generally known as a place where many different opposing forms and concepts (life and death, the individual and society, love and hatred, the animal and human realms, joy and pain, fact and fiction, just to name a few) are put together to form a unique aesthetic experience. Because of the employment of such tools, as well as a good amount of imagination and fantasy, a literary text constitutes a means of escape from our everyday world, with its petty problems, duties and monotonous lifestyle, into a world where anything is possible as long as we understand the rules and principles of why anything is possible. In Ratiani's view, literature is an ideal form of liminality, since it "performs the function of a transitory phase between destructive reality governed by force and the other worldly cosmos worked out by imagination", or in other words, "literature performs the function of a transit coach between the force-driven, chronologically ordered world restricted by technological, bureaucratic reality and a world imbued with faith, free ideas and fantasies" (Ratiani, p. 2). Literature presents a gap between here and there, where "here" is understood as reality or the real and the factual world around us, while "there" is understood as fiction, i.e. something which is different from reality and influenced by fantasy and imagination.

Apart from outlining several types of liminality, Thomassen (2009, p. 18) also stated that liminality can occur naturally, when there was no intention or plan to make it happen (as for example, natural catastrophes, the deaths of people or extinction of animal and plant species), but it can also happen artificially when someone creates it on purpose. An example of an artificial liminality can be seen in cultural rituals during which boys become men, as studied by van Gennep. When we look at artificial liminality from the perspective of literature, especially literature produced in the last couple of decades, we can see that there are authors who intentionally create a boundary between fact and fiction or let their readers know in different ways that what they read is not true or real. Some of them produce texts which lack depth so that readers cannot immerse themselves in the fictitious worlds they seek, or the texts are too short or too complicated to grasp their meaning, or in any other way impossible to understand. What I have just briefly described is a phenomenon known as aesthetic 
distance, which can inarguably be described as a source of liminality, because it represents a gap between fact and fiction, and thus a problem the reader has to face and solve in order to mature, just like a boy has to overcome various obstacles and challenges in order to become a man.

\section{The concept of aesthetic distance}

Aesthetic distance is generally understood as the opposite of aesthetic illusion, which in Werner Wolf's own words “consists predominantly of a feeling, of variable intensity, of being imaginatively and emotionally immersed in a represented world and of experiencing this world in a way similar (but not identical) to real life" (2013, p. 51). Bearing in mind the fact that aesthetic distance is a counterpart of aesthetic illusion, it can be very simply characterized as the breaking of illusion. Illusion-breaking works of art most often have a meta-referential or self-referential quality, which means that they put emphasis on the process of their creation rather than on the development of the plot or the characters and thus interfere in their recipients' immersion in the worlds they represent. This technique was masterfully employed, for example, by John Barth in his short story Lost in the Funhouse (1968), in which the author intentionally interrupted the story of Ambrose and his family's trip to Maryland funhouse with references to grammar or language used in the process of writing the story. As such, Ambrose's experience in the funhouse cannot be viewed as the main focus of the narrator - as it usually would be in traditional literary pieces - but it serves as a base upon which he can comment on the process of creating the story.

In other literary works, the experience of illusion is also inhibited by the portrayal of socalled impossible worlds, i.e. worlds which deny the basic laws of logic, chronology or space and thus create bizarre, unnatural and impossible settings (Ryan, 2013, p. 131). The inconsistency and difficulty in accessibility such texts create can be overcome only by adopting a special attitude towards them which should be based on the ability to move back and forth between the partial universes of the texts and regarding them as a writing experiment which pushes back the limits of what is textually possible. Even though it is not easy to find many examples of such experimental texts, there still exist a few which can serve as model examples of impossible worlds. Manipulation of time can be experienced in Counterclock World by Philip K. Dick (1961), where time flows in the opposite direction, just like the title of the novel suggests. "Characters die before they are born, conversations start with good-bye and end with hello, healthy people get sick after a visit to the doctor" (Ryan, 
2013, p. 138). On the other hand, the manipulation of existence, or a so-called ontological impossibility, can be nicely illustrated by Woody Allen's works, such as the short story entitled The Kugelmass Episode (1977), in which he creates a fictional world which contains another fictional world within it. In the story, Mr. Kugelmass, a humanities professor dissatisfied with his current life, uses the magical powers of The Great Persky to enter the world of Gustave Flaubert's novel Madame Bovary and experience an unforgettable love affair with the beautiful Emma herself, who later visits the modern world of Kugelmass. The short story is thus based on the juxtaposition of two different literary worlds which merge by importing literary characters into other literary texts.

These types of impossibility, as well as meta-referentiality, undoubtedly serve as inhibitors of aesthetic illusion. The worlds that these texts present are not a whole, but rather divided into several smaller units. This is the main reason why they are a challenge to the recipients' imagination. One of the principles of illusion-making describes the complexity and accessibility of the constructed worlds (Wolf, 2013, pp. 40-44), which in the case of these experimental texts is not obeyed. The worlds are not complex, but incoherent and inconsistent, and they are not easily accessible, because they present many obstacles the human imagination has to overcome in order to experience the atmosphere of the constructed worlds, its characters and events. However, it does not mean that these texts are not readable or enjoyable. It takes more effort and a different perspective to be able to shift one's attention and imagination back and forth between the small units of the presented worlds.

What these texts have further in common is that they contain gaps or indeterminacies which the reader tends to (unconsciously) fill in, in order to enjoy the reading. When the reader faces such a text, they actually find themselves on the border of two different worlds - their own one and the fictitious one presented by the text. From this point of view, it is a liminal situation the reader needs to go through to reach the moment of understanding - an imaginary state of being complete after the transition phase. The process of filling in the textual indeterminacies was studied by Roman Ingarden, a Polish phenomenologist whose findings were later adopted by Wolfgang Iser, who is discussed below. Ingarden called the process concretization, which refers to "any complementing determination, any initiative taken by the reader to fill in a place of indeterminacy" (Holub, 1984, p. 26). Since the concretization takes place mostly unconsciously and is strongly influenced by the reader's own personality, background, current flow of feelings and previous experience with life situations and reading, each product of the concretization process, or in other words, each text filled in by the reader 
is unique and unrepeatable. "Filling in indeterminate places requires creativity, [...] skill and perspicuity as well. Moreover, since concretizations are considered the activity of individual readers, they can be subject to vast variation. Personal experiences, moods, and a whole array of other contingencies can affect each concretization. Thus no two concretizations are ever precisely identical, even when they are the product of the same reader" (ibid., p. 26).

\section{Wolfgang Iser's approach to literary analysis}

Ingarden's approach to text signifies that he does not consider it an ultimate product which cannot be modified in any way, but rather as a particular form a reader can work with, cooperate with and play with in order to get its meaning. Ingarden looks at the text from a phenomenological perspective, which means, to put it simply, that it does not exist separately or independently from human consciousness but has to be perceived or understood in the human consciousness in order to be relevant. This premise has been adopted by Wolfgang Iser, a German literary scholar known for his reader-response criticism in literary theory. Similarly to Ingarden, Iser is concerned with an individual text and how readers relate to it, or, in other words, how readers work to grasp its meaning. Iser believes that the relationship between a particular text and its reader differs from the relationship between the same text and a literary critic. He argues that while a critic searches for the hidden meaning in a text because the hidden meaning is viewed as the final product of the text which needs to be defined, for a reader, the process of searching for the meaning is rather an effect of the cooperation between him and the text. In Iser's own words, “[s]uch a meaning must clearly be the product of an interaction between the textual signals and the reader's acts of comprehension. And, equally clearly, the reader cannot detach himself from such an interaction; on the contrary, the activity stimulated in him will link him to the text and induce him to create the conditions necessary for the effectiveness of that text. As text and reader thus merge into a single situation, the division between subject and object no longer applies, and it therefore follows that meaning is no longer an object to be defined, but is an effect to be experienced" (Iser, 1980, pp. 9-10, italics mine).

Iser considers a literary work neither a finite or complete text nor the product of the reader's sole subjective activity; it is rather a combination of the two. Therefore, in order to perform his investigations of this issue, Iser selects three areas of research (Holub, 1984, p. 84). The first one deals with the text and the way it allows and manipulates the production of meaning. What serves as an object of interest for Iser in this matter is the realization of the 
fact that literary texts are written in a code which the reader needs to detect and decipher in order to understand the meaning of the text. The discovery of the code is the first step towards the understanding of the references made in the text, as well as various social and cultural conventions which the text presents in a new, unexpected or untraditional way (Iser, 1980, pp. 60-61) in order to achieve the final goal: "to defamiliarize the familiar" (Holub, 1984, p. 88). The second area of research investigates the processing of the text. Here the main focus of the researcher is the reader and particularly their approach to the text, involving their presence in the text, their image-making ability and the usage of previous experience and memories to process the text they face. Finally, the third area focuses on the communication between the text and the reader; it deals with the interaction or cooperation between these two elements. What Iser stresses here is that the communication between the text and the reader is of a unique nature, because unlike typical face-to-face communication in which two people perceive and guide each other to reach an understanding, within literary communication the reader can never know whether their understanding is correct. That is why the text needs to guide the reader in a certain way and allow them to ask questions or comment on the story. For this purpose, Iser places the so-called blanks (gaps or indeterminacies) in an important position within the communicatory situation.

In the following paragraphs, my aim is to study selected short stories written by Richard Brautigan, Bryan Caron and Lydia Davis, using Iser's aforementioned approach to literary texts. What connects all the short stories I selected for the study is not only the fact that they may be called untraditional or experimental (based on the writing style, theme or length), but they are also examples of aesthetic distance, since their authors use various techniques and tools to make the readers feel unable to connect to the text for several reasons. Some of the texts are too short for the reader to build a clear image of the situation and characters and therefore leave a lot of space for the reader to fill in the missing details (or in certain cases to complete a major part of the missing text), the other texts take advantage of a cyclic narrative style; they blend factual and fictional themes or employ images that are impossible to understand because they are not logical and simply go against what we perceive as natural and inevitable. Because of that, the readers often find themselves on the border of reality and fiction, or in other words, they occupy a liminal space where they have to act in a certain way to either grasp the meaning of the text to become immersed in it or take a step back and let the text live its own life without them. While the former case is typical of readers who are never willing to give up and always trying to understand literary texts no matter how difficult they 
are or how many obstacles they have to overcome, the latter case can be seen as a natural consequence of aesthetic distance. Its goal is to "alienate" readers from the fictitious text and rather make them aware of the process of writing a fictitious text or prevent them from getting lost in the story by reminding them of the fact that what they read can never be true, resulting in the readers' boredom, unwillingness or even disgust in continuing to read something that seems to be nonsensical and ridiculous.

No matter what or how many setbacks such literary texts may bring, my purpose is to look at them from the perspective of a reader who is convinced that each text has a meaning and that each text can tell us something about us and the world around us. Iser himself writes that "if fiction and reality are to be linked, it must be in terms not of opposition but of communication, for the one is not the mere opposite of the other - fiction is a means of telling us something about reality" (Iser, 1980, p. 53). Based on this argument, it is easier to understand why these texts seem to be so chaotic or distorted on the surface - they reflect the world we live in these days. Deep down, they have a meaning and it is our, the reader's, job to find it and understand it.

\section{(1) The text and its potential to allow and manipulate the production of meaning}

As already mentioned above, in the first area of research, Iser focuses on the code in which a literary text is written while stressing that it is important to understand the code in order to grasp the meaning of the text. What the code includes is the selection and use of conventions, which may be called the repertoire of the text. Iser says that "the repertoire consists of all the familiar territory within the text. This may be in the form of references to earlier works, or to social and historical norms, or to the whole culture from which the text has emerged" (Iser, 1980, p. 69). What is, however, important to realize, is the fact that the authors of literary texts not only employ various cultural, social or literary conventions, but they use them in new, untraditional and modified ways. "In the literary text they thus become capable of new connections, but at the same time the old connections are still present, at least to a certain degree (and may themselves appear in a new light); indeed, their original context must remain sufficiently implicit to act as a background to offset their new significance" (ibid., p. 69).

The manipulation of conventions in order to introduce their modification can be seen in Bryan Caron's short story entitled A Story With No Beginning (2002). As the title suggests, the story, which is actually supposed to be a fairy-tale, lacks a beginning, because the 
conventional introductory line 'once upon a time' [ha]s become such a cliché among the tales of the fairy it's almost retching" (Caron, p. 1). What such a literary convention results in is that the author is forced to look for a new and catchy introductory sentence, which would be gripping but not too revealing as regards the story and its characters. The author writes the story in a cooperative mode, which means that several times throughout the story, he reaches out to his readers to get their approval or disapproval of the many ways he wants to begin the story, ranging from a line revealing the twist in the story, to a dialogue, to a description of nature, until he finally ends up with the traditional "once upon a time" line - because at last he cannot think of anything better - while asking his readers to help him decide which one of his suggested introductory ways should be used.

From the perspective of literary convention, the introductory line is not the only one that the author finds old-fashioned and dull. Another is the closing "they lived happily ever after" line which the author comments on in the following way: "Ending my tale with 'happily ever after' is sloppy, boring, and downright vomitous. But why am I worried about the end when I haven't even come up with a suitable beginning?" (Caron, p. 1).

Caron's intention in the short story is to bring about a slight change or modification in the way fairy tales have been written. He works with the conventions built around the beginning and ending of a fairy tale and tries to overcome their seemingly outdated look by trying to introduce something innovative. Why would he do that? For centuries, fairy tales have started and finished in the same way and no one has ever protested against it, so it is clear that the meaning of the attempted modification should be found. Taking into consideration Iser's belief that literature represents reality, it can be claimed that what Caron tried to do in his text was to evolve the fairy tale in a way similar to the evolution in society, technology and culture of the present day. Contemporary people have become used to changes, which happen literally on a daily basis, and therefore a change in the way literature is written is understandable. If the authors want people to read their works, they need to look for innovativeness and attractiveness, otherwise the potential readers may forget about literature and turn to something more exciting.

What does Caron's short story mean in terms of liminality? In fact, it is not difficult to understand the author's intention in writing it, plus it is written in a humorous and engaging manner, so it is easy to read. What makes the reading liminal, however, is the fact that there is basically no plot to follow and no detailed description of characters, which, were they there, would make the process of immersion relatively effortless. Because of this, the reader cannot 
get emotionally involved in the story, which is the natural prerequisite of aesthetic illusion. Moreover, the author's constant addressing of the reader as well as the use of questions and exclamations to comment on the building of the fairy tale's beginning make the reader aware of the reading (and writing) process from the beginning until the end of the short story. ConsequentlyB, they feel distanced from the text and thus on the edge of reality and fiction. On the subject of fairy tales, one of Richard Brautigan's short stories, Homage to the San Francisco YMCA, (from his collection "Revenge of the Lawn", 1971) not only starts with the traditional "once upon a time" line but also carries a fairy tale-like plot, although less romantic (there are no princes or princesses, no victory of good over evil and no happy ending) and more chaotic. It could be called a fairy tale for adults, since its meaning would probably not be correctly understood and warmly welcomed by a younger audience. To sum up the plot briefly, it tells of a retired old man from San Francisco who is a huge admirer of poetry and reads it every day. He loves poetry so much that one day he decides to replace the plumbing in his house with the poetry of John Donne, Emily Dickinson, William Shakespeare and Vladimir Mayakovsky, among many others. However, when he wants to take a bath or do the dishes, nothing works and the man realizes that poetry cannot replace the plumbing. He wants to put the plumbing back, but the poetry refuses to go. The man starts to argue with the poetry and says: "But I have to have plumbing, real plumbing in this house. Did you notice the emphasis I put on real! Real! Poetry just can't handle it. Face up to reality" (Brautigan, 1971, p. 37). Though nonsensical and logically impossible, Brautigan's short story stresses the importance of maintaining a healthy approach to fiction. In other words, it challenges the extreme pole of aesthetic illusion, when the reader immerses themselves in a work of fiction so deeply that they absolutely forget its fictitious quality and consider it real; a condition which could be called aesthetic delusion. A reader who approaches literary works from a healthy perspective, meaning that he purposefully keeps a certain amount of distance, even when he wants to experience aesthetic illusion, knows that Brautigan's short story is written in a code, the solution to which helps them grasp the meaning of the story. Moreover, it is written in a way which constantly has the reader situated in a liminal space, since even though the plot is gripping and engaging (and thus may cause aesthetic illusion); the ending of the story reminds the reader of the fact that no matter how immersive literature is, it can never replace reality (and thus create aesthetic distance). The liminality of the short story is supported even from the perspective of possibility and impossibility. The illogical blending of poetry with the man's reality and the nonsensical fight of the man with poetry makes the story 
an illustration of an ontological impossibility. Literary genres or characters cannot live in our reality; they can occupy only the space created for them within their literary environment. This rule is logical and natural for us, and therefore its breaking stands out as controversial and absurd, which in the long run distances us from the text.

As can be observed in the short stories discussed above, the authors employ a certain code to send a particular message to their readers. And even though the texts are easy to read thanks to the humorous and engaging style they are written in, their message can appear confusing to an inexperienced reader or a reader who does not read between the lines. That is the reason why it is sometimes necessary to search for the code by using literary, social and cultural conventions as the basis of our investigation and studying the text in detail in order to grasp the meaning of the story. According to Iser, being able to do this is the first step towards the understanding of literary texts. In the second area of his research, he also takes a look at the reader's ability to form images in his mind, to imagine the scenes and move mentally through the text. This is what I focus on in the following section.

\section{(2) The processing of a literary text}

The processing of a literary text is a phase in reading which applies especially to the reader and his ability to work with the hints implied in the text and form adequate mental images in his mind. However, Iser says that this process is not only about the reader but is more or less based on cooperation between the reader and the literary text: "Any successful transfer [...]though initiated by the text - depends on the extent to which this text can activate the individual reader's faculties of perceiving and processing. Although the text may well incorporate the social norms and values of its possible readers, its function is not merely to present such data, but, in fact, to use them in order to secure its uptake" (Iser, 1980, p. 107). That being said, reading is not a one-way process but the result of an interaction between the text - in which the author uses various techniques and tools to activate the reader's imagination - and the reader - who employs his mental abilities as well as existing experience of life and reading to imagine and understand the literary images constructed in the text. In this sense, literature can be viewed as a certain game between the text and the reader, where one element influences the other, while, at the same time, one element is incomplete without the other. In the course of literary development, this particular issue has been accepted and promoted by numerous authors, such as Laurence Sterne, the author of the unconventional novel The Life and Opinions of Tristram Shandy, Gentleman (1759), who said: “... no author, 
who understands the just boundaries of decorum and good-breeding, would presume to think all: The truest respect which you can pay to the reader's understanding, is to halve this matter amicably, and leave him something to imagine, in his turn, as well as yourself. For my own part, I am eternally paying him compliments of this kind, and do all that lies in my power to keep his imagination as busy as my own" (in Iser, 1980, p. 108). The timelessness of Sterne's opinion was further supported by the French existentialist Jean Paul Sartre in the 20th century, who claimed that "when a work is produced, the creative act is only an incomplete, abstract impulse; if the author existed all on his own, he could write as much as he liked, but his work would never see the light of day as an object, and he would have to lay down his pen or despair. The process of writing, however, includes as a dialectic correlative the process of reading, and these two interdependent acts require two differently active people. The combined efforts of author and reader bring into being the concrete and imaginary object which is the work of the mind. Art exists only for and through other people" (in ibid., p. 108).

The cooperative principle should be applied in literature in general, since as a rule, a literary text which reveals too much and thus does not let the reader participate in putting the finishing touches to the images it conveys, may easily discourage the reader and end up causing boredom and even disgust. On the other hand, a literary text which leaves a lot of space for the reader's imagination can be discouraging as well because due to the lack of hints and support in the text, the reader's creativity and imagination is not controlled and thus may overflow beyond the boundaries of what the author initially intended to achieve. That being considered, the golden middle way should be followed even in literature.

In the following literary texts, my aim is to look at the way their authors engage in the game of image-making and how they cooperate with readers. Taking into consideration the fact that these texts are built on the liminality of fact and fiction, and therefore challenge the creation of aesthetic illusion, it can be presumed that the cooperation principle is employed in them very loosely, which means that the reader is allowed to imagine things rather freely. The question is whether the reader's imagination is somehow placed within boundaries by the text itself or whether the reader is the one who truly finishes the text, as opposed to the author.

The American short-story writer Lydia Davis (born in 1947) is famous for her specific writing style, which is very brief and very concise. In fact, there is no problem in copying her texts here in their entirety. Despite writing in such an economical style, her genius lies in her ability to express much more than is written. In her short stories, Davis relies on readers' 
everyday experience, which undoubtedly helps them in the process of looking for the meaning of her texts.

One of Davis's short stories - a two-liner, obviously - is called Spring Spleen and it goes like this: "I am happy the leaves are growing large so quickly. Soon they will hide the neighbor and her screaming child" (Davis, Spring). Though from the point of view of liminality, this text is positioned on the edge of fact and fiction, since its briefness does not allow the reader's immersion in it, if we read between the lines, we can reveal a surprising (or probably shocking) meaning. In fact, what seems to be a humorous description of something actually turns to seriousness. The image of a growing plant - probably a tree or a bush - gradually hiding the view of a neighbouring estate - reveals a huge number of feelings the unknown narrator (which could be either a man or a woman) bears deep inside. However, these feelings are negative, since the narrator claims to be happy at no longer seeing the neighbour and her child. This is what the reader understands on the surface. In order to grasp the meaning thoroughly, the reader needs to go deeper and ask questions which would help them understand who the narrator is, what causes his/her feelings, who the neighbour is, why her child screams so much or what has happened between the narrator and the neighbour. Of course, these questions will not be answered in the text, but the reader is intentionally led to search for the answers on their own, employing their own feelings, perceptions and experience in the process. The text leaves a lot of space for the reader's creativity and imagination, and in this way allows them to complete it on their own. That being said, and considering that everybody has different experience as well as a unique personality, the resulting completed text will certainly have an innumerable number of variations, even when created by the same reader, since every day our feelings and moods change as does our current opinion about the world and life.

A similar technique is used in Davis's other short story entitled Notes During Long Phone Conversation with Mother (Davis, Notes). Again, the text is very short and seemingly chaotic, but contains an interesting meaning inside. This is what the whole text looks like:

for summer she needs

pretty dress cotton

cotton nottoc

coontt 
Ars Aeterna - Volume 9/ number 1/ 2017

tcoont

toonct

tocnot

tocont

tocton

contot

As is clear from the layout of the text, the words are purposelessly scattered across the page, as if the person (a daughter or son) listening to their mother talking about the cotton dress needed something to entertain themselves with during the (long) phone conversation. This text shows yet again that Davis builds on people's experience and habits - in this case a bad habit or a subconscious act of writing or doodling while talking on the phone with someone. Now, what the reader needs to do is search for the meaning of such an activity, not only in daily life, but also in this specific literary text. Based on the title of the short story, the layout of the text, the spelling of the individual words and the gradual vanishing of the meaning of the words, the reader realizes that the listener is becoming more and more bored with what the mother is saying and thus entertains themselves with the reordering of the letters in the word "cotton". Again, this is what the reader perceives on the surface. In order to give the text its meaning, the reader has to understand why such an activity accompanies the phone conversation. Using their creativity and image-making ability, the reader may think that the mother is a bit of a talker who does not give her daughter/son much space to express herself/himself and thus she/he needs something to occupy herself/himself with. Another possibility, among several others, is that the daughter/son has lost patience with the mother or even interest in her, and therefore chooses to spend time doing something more interesting.

While both texts by Davis seem to be limited in terms of how much meaning the author provides in them, it is still possible to subjectively relate to the frame given in the texts and fill in the missing information on our own, using our creativity and imagination. The fact is that the cooperation between the author and the reader is not perfect, since the author of the text does not answer the questions which arise from our attempt to get to the details; but we have to bear in mind that this was the author's purpose - she wanted us to actively participate in the process of creating and completing the story she indicated in the provided frame. It is a challenge for the reader, but using everyday experience and memories, this process does not seem to be too complicated to execute. On the other hand, the lack of details and the briefness of the text may serve as discouragement and unattractiveness for readers who do not want to 
be mentally active in the process of reading, and thus such a text can easily cause the creation of aesthetic distance.

No matter how inaccessible Davis's stories appear at first sight, when they are compared with certain stories written by Richard Brautigan, they still seem relatively rich in detail. One of Brautigan's (very) short stories is called Lint and it goes like this: "I'm haunted a little this evening by feelings that have no vocabulary and events that should be explained in dimensions of lint rather than words. I've been examining half-scraps of my childhood. They are pieces of distant life that have no form or meaning. They are things that just happened like lint" (Brautigan, 1971, p. 68). What differentiates this short story from the ones by Davis is that in this text the author writes about his own childhood (and not about issues from people's everyday life experience), which means that we cannot relate to it, unless we are familiar with it. This is the reason why this text may appear unattractive and distancing to us. In other words, there is nothing in the text which would draw us further and make us long for the revelation of what concerns the author when writing it. Of course, we may ask questions and make assumptions about what might have happened in his life, but since this matter is not known to us, not even from a distance, and the author does not provide any hints for us to help us find the answers to our questions, the text as such cannot be viewed as anything else other than an initiator of aesthetic distance. In other words, no matter how hard we try to employ our creativity and image-making ability, a lack of answers will always lead to disappointment, because our reading expectation - i.e. the desire to learn something new and become immersed in a fictional world - is not fulfilled.

Compared to Lint, Brautigan's other short story, this time a bit longer and much more detailed, entitled 1692 Cotton Mather Newsreel, is written in a more immersive style. It tells of the author's childhood experience when he was forced by his friends, in a game of dare, to go inside the house of a woman they collectively called a witch and wave at them from the window of her room. While reading this story, the reader has practically no problem following the plot and mentally portraying the images described in the story, so the text appears extremely interesting, even captivating. As the boy's brave attempt to enter the witch's room is described, the reader's imagination is gradually wrapped in suspense and a thrill, because the witch could show up at any time and curse the young intruder for the rest of his life. From the perspective of image-making and the creation of a tense atmosphere, the story generates the effect of aesthetic illusion. In other words, it has the reader lost in the story. This effect continues until the very end, when the boy successfully completes the dare 
and then something quite unexpected happens: "I turned around in that house which was like a shallow garden and all my fears collapsed upon me like a landslide of flowers and I ran screaming at the top of my lungs outside and down the stairs. [...] When I came screaming around the side of the house, my friend jumped up from the gutter and started screaming, too. I guess he thought that the witch was chasing me" (Brautigan, 1971, p. 11). At this point, the reader's imagination, which was involved in the image-making process rather subconsciously until the final twist, takes on another task: to find the reason behind the boy's sudden emotional breakdown. The author does not provide any explanation for this, and instead leaves a space for the reader to fill in the missing detail and make the story complete. Who was the "witch"? Did she find the boy in her room? Did she really chase him? Why did the boy start screaming when he should have felt heroic for successfully completing the challenging dare? All these questions suddenly appear in the reader's mind and subsequent creativity can proceed... until the reader gets to the last line of the story which says: "This was a month or two before the German Army marched into Poland" (ibid., p. 11). Of course, it is generally known that this event sparked the Second World War, but still what remains mysterious for the reader in this story is the question why the author decided to end the story this way. Now, all of a sudden, the entire story can appear symbolical, with the angry witch standing for the Germans, or the boy's intrusion in her house standing for the Germans' intrusion into Poland. Maybe the last line has nothing to do with the story, and the author used it just to set his childhood memory in time or to confuse the reader. In all cases, however, this one line causes the reader's concentration and mental participation in the story to be upset, and thus the reader is returned back to reality and distanced from the story they were reading and trying to emotionally and imaginatively penetrate.

The situation which takes place at the end of the last discussed short story by Brautigan is what Iser calls the "wandering viewpoint". Iser defines the concept as "a means of describing the way in which the reader is present in the text" (Iser, 1980, p. 118). It means that, as readers, we constantly perceive and evaluate the events we read about in terms of our own experience and past memories, as well as against our expectations for the future. Holub writes that "an unexpected occurrence will therefore cause us to reformulate our expectations in accordance with this event and to reinterpret the significance we have attributed to what has already occurred" (Holub, 1984, p. 90). In the story about the boy and the witch, the final line does exactly what Holub claims; i.e. it makes the reader go through the story once again and try to find the meaning of it in connection with what the final line says. While doing so, the 
reader's viewpoint wanders back and forth across the whole story to ponder over various possibilities that the final line may suggest. "The wandering viewpoint thus permits the reader to travel through the text unfolding the multiplicity of interconnecting perspectives which are offset whenever there is a switch from one to another" (ibid., p. 90).

The relationship between the reader and the author in all the literary texts discussed in this section is one of cooperation, though the scale of it differs in each individual text. The basis of the cooperation is the amount of freedom an author gives the reader to make his own contribution to the text, using his unique experience, creativity and imagination. As could be observed in the texts discussed above, while in some cases the reader was able to fill in the missing details relatively easily thanks to the fact that the story was relatable to their life, there are texts which are impossible to complete due to their narrow theme or subject matter that is not familiar to the reader. In both cases, however, the author has to bear in mind that a text which is too short and proposes only a frame story creates the effect of aesthetic distance, because the reader cannot become fully involved in the story they are reading for the sake of having to fill in what is missing in it. In fact, anytime the reader realizes the lack of the story's details and is forced to be active more than they would consider desirable in having the story in its complete form, the reader distances themselves from the fictitious world portrayed in the story and returns back to reality, and thus faces a liminal situation.

\section{(3) The communicatory structure of a literary text}

The issue discussed in the section above is linked with the third area of Iser's research, which has to do with literary communication; or, in other words, with the interaction between the text and the reader. In this area, Iser deals with the way a literary text differs in its communicatory aspect from "normal", everyday communication. He claims that "an obvious and major difference between reading and all forms of social interaction is the fact that with reading there is no face-to-face situation. A text cannot adapt itself to each reader with whom it comes into contact. Partners in dyadic interaction can ask each other questions in order to ascertain how far their views have controlled contingency, or their images have bridged the gap of inexperienceability of one another's experiences. The reader, however, can never learn from the text how accurate or inaccurate are his views of it" (Iser, 1980, p. 166). Based on this explanation, it can be said that there are two main areas in which literary communication differs from the ordinary, face-to-face one. Firstly, the entire interaction between the reader and the literary text takes place through a page (or electronic page) and since the page cannot 
speak, the reader cannot get answers to their questions to support their understanding of the text, nor can they test whether their ideas match the ideas initially intended by the author of the text. And secondly, there is no communicatory context between the reader and the text which would facilitate the understanding of the text. Therefore, in order to compensate for the lack of these two areas, the author has to come up with other ways how to guide and control the reader, at least to a certain extent. For this purpose, Iser selects blanks (also known as gaps or indeterminacies) to guarantee the successful fulfilment of the process of literary communication.

Iser does not provide a clear definition of what the blanks stand for, but generally, it can be said that blanks appear whenever there is a break in the plot or in the theme, and the reader has to fill in the missing part to make the text complete (Holub, 1984, p. 93). As was mentioned in the previous section, the existence of blanks in literary texts can prove nothing but beneficial, because they make the reader do his part in the completion of the text, and thus be actively involved in it. Indeed, all the texts studied above contain a blank, which means that the reader finds themselves involved in the process of finding out why the narrator/protagonist of the story acted in a particular way. In the following paragraphs, I look at two short stories by Richard Brautigan, in which one contains a blank in the plot and the other contains a blank in the theme.

The first story to be discussed is called The Scarlatti Tilt (1971). It is a two-liner, something similar to Davis's work, which provides the frame of a story and leaves much space for the reader to fill in: "'It's very hard to live in a studio apartment in San Jose with a man who's learning to play the violin.' That's what she told the police when she handed them the empty revolver." (Brautigan, 1971, p. 29). At first sight, the text can be classified as too short to form an immersion or aesthetic illusion. In fact, its briefness and an obvious lack of detailed descriptions appear distancing, even for an experienced reader. What is, however, important to realize is the fact that the text provides the basis upon which a reader needs to make his own contribution to the text. The reader knows where the story takes place, who the people involved in it are, as well as what happened. What they do not know from the text is the detailed characterization of the characters and what exactly happened between the two people before the tragedy. This is one giant gap that the reader is expected to make up and complete. In other words, there is a gap in the plot, and its completion is controlled by the boundaries of what is written in the text, or the frame of the story. Of course, the text cannot help the reader in terms of answering their questions directly; it does not support them when 
they create something appropriate or bring them back when they become misled by his lively fantasy. The reader must bear in mind that all the time they contribute to the story, they have to be limited by the frame of the story.

In order to make this one-sided communication work, i.e. to come to its satisfactory ending as in "normal" communication between two or more people, a reader has to divide the text into several smaller units, complete the units using his own imagination and then join the units together to form a whole. Taking this two-liner by Brautigan as an example, the reader can proceed in the following way: first it is necesary to fill in the missing information about the man and the woman (who they are, what their background is, how old they are, what job they have, what relationship they have, etc.); then the reader can think about the time they have spent living in the studio apartment together and when the first problems started, as well as if and how they were dealing with them, i.e. the reader should imagine everything that happened before the woman shot the man; and finally the reader can use his creativity to recreate the scene of the murder (how it happened step by step) and what followed shortly after (the woman's immediate actions, the arrival of the police, the arrest and trial).

The act of filling in the missing information, in this case much of the plot, goes hand in hand with Iser's concept of the wandering viewpoint, because throughout the construction of the missing plot, the reader moves back and forth in the story while trying to make links between various imagined elements and uses their own life and reading experience to do so. This is where the reader's participation in the creation of the story arrives at its highest point, as well as their involvement in successful literary communication.

In the second short story written by Brautigan, September California (1971), the author uses two different images - a woman lying on the beach, sunbathing, and a ship leaving the San Francisco Bay. He blends these two scenes to create one unified scene, and gives the reader an opportunity to understand its meaning on his own. The writing style of the story is particularly interesting - there is basically no plot, only descriptions which overlap. It means that in the process of describing the woman enjoying her time on the beach the narrator swiftly moves on to describing a leaving ship which he happens to see from his perspective, in the background to the woman. He does this by skipping back and forth between these two images, as in the following concluding extract: "Her hair is the same color as the ship. I can almost see the captain. He is saying something to one of the crew. Now she takes the thermometer out of her mouth, looks at it, smiles, everything is all right, and puts it away in a little lilac carrying case. The sailor does not understand what the captain said, so the captain 
has to repeat it" (Brautigan, 1971, p. 77). After finishing the text, the reader should realize that their task is not to make up the plot, because there is no frame with hints to suggest what needs to be filled in, but the gap appears in terms of the theme. It means that the reader is expected to use their experience to find out why the author decided to mix these two, seemingly not related, images. Was it to emphasize the opposition of relaxed and fast lifestyle, or the opposition of monotony and new challenges (the former represented by the image of the woman lying on the beach and the latter by the ship leaving port)? These are just two of the possible themes the short story may convey, considering that each reader is unique and thus sees different themes in the story, based on particular experiences in life as well as current feelings and mood.

During the process of filling in the missing details, whether it is a plot or a theme, the reader finds themselves in a liminal position. This is because a story which does not provide thorough information seems incomplete, and a lot of space left for the reader's imagination means that the reader is reminded of the fact that the fictitious world they would like to dive into is actually connected with the reality around them. It means that the reader needs to look around them as well as to their past experiences and use them as tools to complete what is missing in the text. However, from the perspective of Iser's research, this process is a vital part of literary communication. Iser did not study aesthetic distance or the liminality between fact and fiction; his aim was to look at the process of reading from the perspective of the reader and how he proceeds to grasp a literary text and its meaning. The perspective used in this paper, on the other hand, takes into consideration the limitations or barriers which the reader needs to overcome in the reception process and in order to make the literary communication truly successful.

\section{Conclusion}

Even though all the analysed literary works are written in a singular style and portray different themes, they have one thing in common: the artificial creation of liminality. It means that using various tools and techniques, the reader is placed in a situation where they have to overcome many setbacks in the process of understanding a literary work and grasping its meaning. The setbacks I am speaking of are related to the creation of aesthetic distance, which causes the reader to face difficulty in their attempt to become mentally and imaginatively involved in the literary text they are reading. The following table summarizes the ways 
aesthetic distance is built in all the works studied in this paper, and shows the types of liminality I was able to detect in them:

\begin{tabular}{|c|c|c|}
\hline Short story & Aesthetic distance caused by & Liminal situation between \\
\hline $\begin{array}{l}A \text { Story With No } \\
\text { Beginning }\end{array}$ & $\begin{array}{l}\text { - author's } \\
\text { involvement in the } \\
\text { process of writing the } \\
\text { story } \\
\text { - author's notes } \\
\text { and comments } \\
\text { interrupting the flow of } \\
\text { the narrative }\end{array}$ & $\begin{array}{l}\text { reality and fiction } \\
\text { - } \quad \text { immersion and } \\
\text { distance }\end{array}$ \\
\hline $\begin{array}{l}\text { Homage to the San } \\
\text { Francisco YMCA }\end{array}$ & $\begin{array}{l}\text { - blending of } \\
\text { poetry and reality } \\
\text { - } \quad \text { ontological } \\
\text { impossibility }\end{array}$ & $\begin{array}{l}\text { - logically possible } \\
\text { and impossible } \\
\text { - immersion and } \\
\text { distance }\end{array}$ \\
\hline Spring Spleen & $\begin{array}{l}\text { - briefness of the } \\
\text { text } \\
\text { - lots of missing } \\
\text { details }\end{array}$ & $\begin{array}{l}\text { - what the reader } \\
\text { knows and what they } \\
\text { have to fill in on their } \\
\text { own }\end{array}$ \\
\hline $\begin{array}{l}\text { Notes During Long } \\
\text { Phone Conversation } \\
\text { with Mother }\end{array}$ & $\begin{array}{l}\text { - chaotic layout of } \\
\text { the text } \\
\text { - briefness of the } \\
\text { text } \\
\text { - lots of missing } \\
\text { details }\end{array}$ & $\begin{array}{l}\text { - what is given and } \\
\text { not given }\end{array}$ \\
\hline Lint & 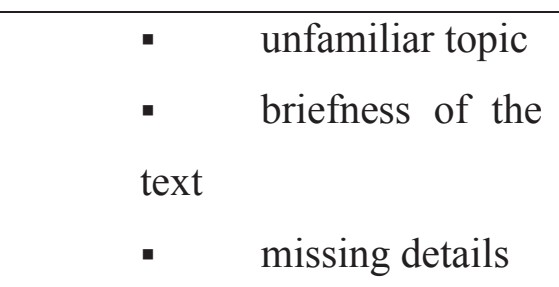 & $\begin{array}{l}\text { what the reader } \\
\text { knows and what they do } \\
\text { not know }\end{array}$ \\
\hline $\begin{array}{l}1692 \text { Cotton Mather } \\
\text { Newsreel }\end{array}$ & $\begin{array}{l}\text { - the breaking of } \\
\text { immersion by using } \\
\text { unexpected conclusive } \\
\text { sentence }\end{array}$ & $\begin{array}{l}\text { - immersion and } \\
\text { distance }\end{array}$ \\
\hline
\end{tabular}




\begin{tabular}{|c|c|c|}
\hline The Scarlatti Tilt & $\begin{array}{l}\text { briefness of the } \\
\text { text } \\
\text { - providing of the } \\
\text { frame story only } \\
\text { - missing details }\end{array}$ & $\begin{array}{l}\text { - what the reader } \\
\text { knows and what he does } \\
\text { not know }\end{array}$ \\
\hline September California & $\begin{array}{lr}\text { - mixing } & \text { two } \\
\text { seemingly } & \text { distant } \\
\text { images } & \end{array}$ & $\begin{array}{l}\text { immersion and } \\
\text { distance } \\
\text { - what is given and } \\
\text { not given }\end{array}$ \\
\hline
\end{tabular}

The overall liminal situation which is created in all the studied literary texts, i.e. the liminality between fiction and non-fiction, causes the reader to feel the need to use their imagination and creativity to complete the images drafted in the texts, as well as overcome the distancing effect to achieve at least a partial feeling of aesthetic illusion. This can be done by adopting a perspective from which a literary text which seems chaotic, illogical or incomplete on the surface is understood as the author's attempt to examine what is textually possible. However, such an experiment may result in the reader's unwillingness to do more than they would like to in order to understand the text, or even in a reluctance to read such works at all.

If, however, we understand a liminal situation as a challenge to become a better and more experienced person, such experimental texts may become not only beneficial for our development as readers but also a challenge to our mental faculties, since the lack of details and incomplete images employed in many of these texts require an enhanced imagination and creativity, which, in the long run, proves nothing but enriching in our development as human beings.

\section{References}

Allen, W. The Kugelmass Episode. Available at:

http://www.woodyallen.art.pl/eng/kugelmass_episode.php

Barth, J. 1980. Lost in the Funhouse. Available at:

http://www.massey.ac.nz/massey/fms/Colleges/College\%20of\%20Humanities\%20and\%20So cial\%20Sciences/EMS/Readings/139.105/Additional/Lost $\% 20$ in $\% 20$ the $\% 20$ Funhouse $\% 20$ \%20John\%20Barth.pdf

Brautigan, R. 1971. Revenge of the Lawn. NY: Houghton Mifflin Company. 
Caron, B. 2002. A Story With No Beginning. Available at: http://www.storymania.com/cgibin/sm2/smreadtitle.cgi?action=display\&file=shortstories/Car onB-AStoryWithNoBeginning.htm

Davis, L. Notes During Long Phone Conversation With Mother. Available at: http://fivedials.com/five-short-stories/

Davis, L. Spring Spleen. Available at: https://biblioklept.org/2013/05/06/spring-spleen-lydiadavis/

Holub, R. C. 1984. Reception Theory. Routhledge.

Iser, W. 1980. The Act of Reading - A Theory of Aesthetic Response. The Johns Hopkins University Press.

Ratiani, I. Liminality and the Liminal Theory of Conceptualizing Time and Space in $20^{\text {th }}$ century Eschatological Anti-utopia. Translated by Chanturia, A, pp. 1-17. Available at: http://www.irmaratiani.ge/Liminality,\%20Nabokov.pdf

Ryan, M-L. 2013. "Impossible Worlds and Aesthetic Illusion." In Immersion and Distance: Aesthetic Illusion in Literature and Other Media. Amsterdam: Editions Rodopi B.V., pp. 131148.

Thomassen, B. 2009. "The Uses and Meanings of Liminality." In International Political Anthropology, vol. 2, no. 1, pp. 5-27. Available at: http://www.moodlevda.lt/moodle/pluginfile.php/2205/mod_resource/content/0/8\%20Thomass en $\% 20-\% 20$ Uses $\% 20$ and $\% 20$ meanings $\% 20$ of $\% 20$ liminality.pdf

Wolf, W. 2013. "Aesthetic Illusion." In Immersion and Distance: Aesthetic Illusion in Literature and Other Media. Amsterdam: Editions Rodopi B.V., pp. 1-63.

Natália Čechová

Department of English and American Studies

Faculty of Arts

Constantine the Philosopher University in Nitra

Slovakia

natalia.cechova@ukf.sk 